\title{
Globalized Inclination to Acquire Knowledge and Skills Toward Economic Development
}

\author{
GRIGORIOS L. KYRIAKOPOULOS \\ National Technical University of Athens \\ School of Electrical and Computer Engineering \\ 9 Heroon Polytechniou Street, Electric Power Division, Photometry Laboratory, 15780 Athens \\ GREECE
}

\begin{abstract}
In an era of economic recession and the divulged threats of COVID-19 pandemic in the world a highly impacting socio-economic activity is the education sector. The operational difficulties of companies and organizations, as well as the closure of universities, schools, training courses, are all affecting the entrepreneurial and the learning progress on using workers time and learners facilities to develop their knowledge and to build up their skills. In particular, free time of institutions' closure can become a golden opportunity for learning and progresses in virtual education while adopting e-learning modes of information technology (IT) and supporting the distribution of knowledge and information for training and education. Since the COVID-19 pandemic outbreak only few studies have been devoted on studying the impact of cultural characteristics, economic situations, skills and knowledge on the development and the wider human wellbeing. At this study the literature production of economic development was investigated in the light of the ignored, but critically important, issue of globalized inclination to acquire knowledge and skills. All essential aspects of economic systems and economic development within the COVID-19 era were approached, quantified, and graphically valuated, in the light of the following fields of literature search: "dynamic economic systems", "economic development", "knowledge skills", and "globalization". The measurable indicators of comparing these results were that of: chronological, geographical, languages of reports' written, subject areas, and keywords, accordingly. Besides, the three domains of technology, environment - ecology, and socio-economics were conveyed, while the key-determinants of knowledge and skills acquisition were also analyzed. From a managerial point of view the simultaneous affection of cultural characteristics, economic simulations, skills and knowledge aspects were considered as positive and significant, thus, supporting managers to better understand the necessities of IT development and managing a highly qualified workforce to shift the thread of the COVID19 era while performing feasible learning management to solidify workers' education through formal and inhouse education.
\end{abstract}

Key-words: dynamic modeling; economic development; knowledge and learning, skills' acquisition, COVID19, technology; migration policies; environment; ecology;

Received: March 28, 2021. Revised: September 30, 2021. Accepted: October 20, 2021. Published: November 4, 2021.

\section{Introduction}

An economic environment has a series of variables that make it complex and hard to analyse. Many different aspects have been studied and taken into consideration in the relevant literature. Approaches related to economic environment have been made based on historical data for enterprises in a geographic basin using graph theory principles [1]. In understanding the economic system dynamics modelling theory the properties of national economic systems at different hierarchic levels from universal statistical and mathematical perspective they have been studied [2].
The simplification of mathematical models (macromodels) entails the creation of complex determined dynamic systems in the form of discrete state equations. In such a mathematical approach the possibility of the given propagation on stochastic systems it has been stressed out [3].

Modelling of spatial dynamic economic systems it has been based on inter-regional input-output systems, which explicitly address complex regional economic activities. The economic dynamics of modelling are affected by the feedback given, enabling the exploration of structural changes as internal factors that indicate how the economic 
dynamics might evolve through time and different scenarios of development [4].

From an environment-ecology point of view it is important researchers to investigate whether markets can provide feasible support for ecological restoration, and regulate the conditions under which dynamic modeling can be supportive. Besides to technologies of environmental restoration of natural water-, terrestrial-, air- sources, policy makers and researchers can develop a consistent methodology for economic evaluation of ecological restoration projects [5]. Similarly, the dynamic processes involved at economic systems can be concentrated on the extraction and the use of natural resources required to meet economic needs. Methods of dynamic modeling in economics and microeconomic models of firms should make provision of optimal use of both non-renewable and renewable resources [6].

Another crucial component of the successful performance of an economic system (ECSYS) is the maintenance of an optimum function by applying industrial and economic criteria for a given system. The purpose of such a research is the stochastic modeling of the stability of an ECSYS. ECSYS stability is a process of deterministic and stochastic modelling under uncertainty conditions by using the methods of benchmarking and dynamic programming [7]. In a relevant research it was proposed a dynamic model for evaluation of a Pumped Storage Project (PSP). The optimal expansion policy was determined by considering different alternatives units, including: steam- gasand combined cycle turbines. Based on this dynamic assessment modelling of different alternatives covering a period of more than 20 years and a target Loss of Load Probability (LOLP), a credible economic justification for the PSP was proposed [8].

The generalized approach of economic system development through dynamic modeling can be based on properties of dynamics which assist the improvement of strategic forecasting methodology not only in manufacturing and economic systems, but also in full development of the system in general abiding to new laws that foster an harmonious development [9]. Besides, in alignment with the aforementioned "economic system development", it is noteworthy to denote that the organization for Economic Co-operation and Development (OECD) Corporate Governance Principles has gained worldwide recognition as an international benchmark for sound corporate governance [10]. Among other initiatives and strategic plans the key findings' disclosure from a "Future of Education and Skills" foresight report employed a variety of structured stakeholder consultations, involving experts, policy makers and teachers in different sides, able to consider how and what citizens will learn in 20202030. Such actively used consultations among both OECD and non-OECD countries by governments, regulators, investors, corporations and stakeholders they have been adopted as one of the 12 keystandards for sound financial systems by the financial stability forum. A variety of ways under which the revised principles take into account nonOECD countries' recent insights and findings should maintain their global relevance [10].

This novelty of this study resides to the fact of a combined literature synthesis of prevailing tendencies in the contexts of economy, energy, education, and immigration. In this multiparametric approach an integrated literature search was based on selected keywords at the Scopus search database covering an almost four decades of literature production by using specific key-phrases and allocating the results in five fields of organization. The results showed economic recession and divulged threats of COVID-19 pandemic in the world among the most highly impacting socio-economic activities on education and globalization. Besides, the operational difficulties at companies and organizations worldwide, the closure of schools and universities, the in-person difficulties of training courses, all affected the entrepreneurial and the learning progress. Subsequently, contrary to traditional approaches, novel alternative choices should be proven effective in adding value to workers' time while developing their knowledge and building up their skills under global economic constraints and socio-cultural hindrances.

In section 2 the literature results over the period of were organized by using three specific groups of key-phrases at the Scopus search database. The literature search was conducted at once the second half of the year 2021 covering the search timeframe from 1980-present. Furthermore, in section 2 the literature-referred dynamic models were categorized into the three domains of: Technology, EnvironmentEcology, Socio-Economics. Subsequently, in section 3 the Methods and Analysis were approached in an integrated manner that was focused on acquiring knowledge and learning skills under the conditions of globalization and the opportunities of migration, mainly affected by working constraints and shortages of new positions worldwide. Then, in section 4 the 
Discussion section provided an integrated argumentation of revealing those key-determinants: constraints and challenges of the analysis in alignment with the today situation of global economic recession at the era of COVID-19 pandemic. Conclusively, the constraints, barriers, drivers, challenges and future prospects of the study were creatively addressed at the Conclusions section.

\section{Literature Review}

The literature results were arranged in alignment with the following three groups of key-phrases: a) "dynamic economic systems", b) joint phrases of "economic development" and "knowledge skills", c) joint phrases of "economic development", globalization, knowledge, skills. In particular, these key-phrases at the Scopus search database were organized under the following three groups of investigation:

Group 1: "dynamic economic systems"

Group 2: "economic development", "knowledge skills"

Group 3: "economic development", globalization, knowledge, skills

The graphical representation of this literature search was organized into the following five fields of analysis/areas of comparison: chronological, geographical, languages of reports written, subject areas, and keywords. Subsequently the quantification of the literature results was based on a visual representation and a measurable valuation, all referring to Figures 1-8 and Table 1, accordingly. These findings revealed the dynamic behaviour among the extracted keywords and their corresponding subject areas. All keywords and subject areas provided a new approach of economic systems and economic development under the conditions of acquiring skills and developing knowledge across (a today globalized) world. The chronological evolution of literature results among the groups 1, 2, and 3, it is shown in Figure 1.

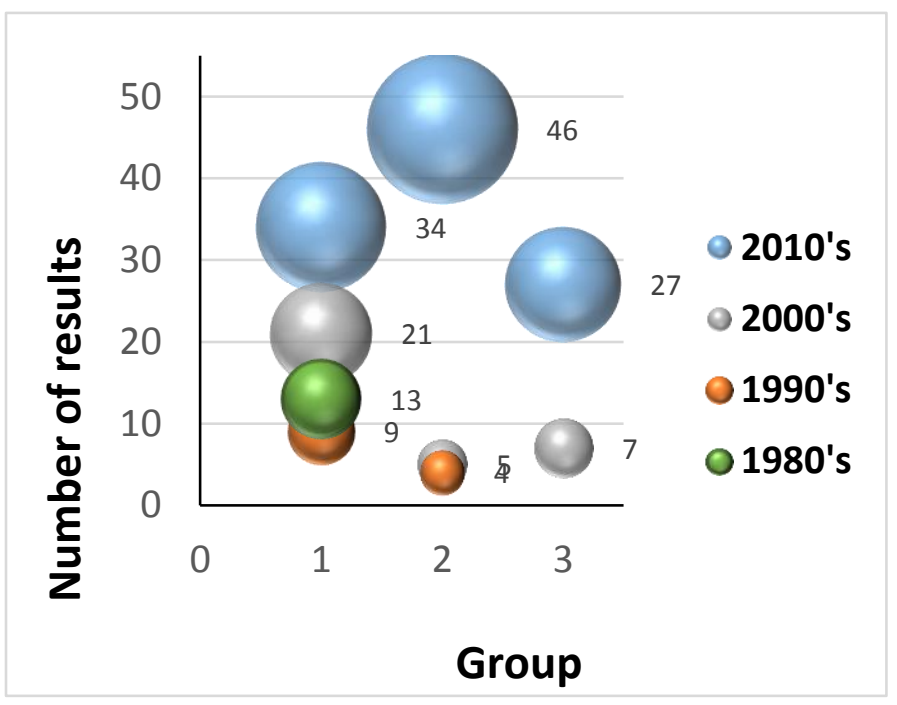

Fig.1. Literature overview per group studied regarding the decade of publication.

From a chronological point of view it is noteworthy a steady, almost 8-times, increase at the plethora of research results from the decade of 1980's up to present. Besides, it was shown a sharp, reaching 5times, increase of literature results in the field of Group 2: "economic development", "knowledge skills", followed by a smoother, almost 4-times, increase in the relevant field of Group 3: "economic development", during the same period of published results. In the same period a gradual, but smoother, publication increase of Group 1 results on: "dynamic economic systems", implying the credibility of dynamic models to interpret economic systems worldwide, Figure 1. 


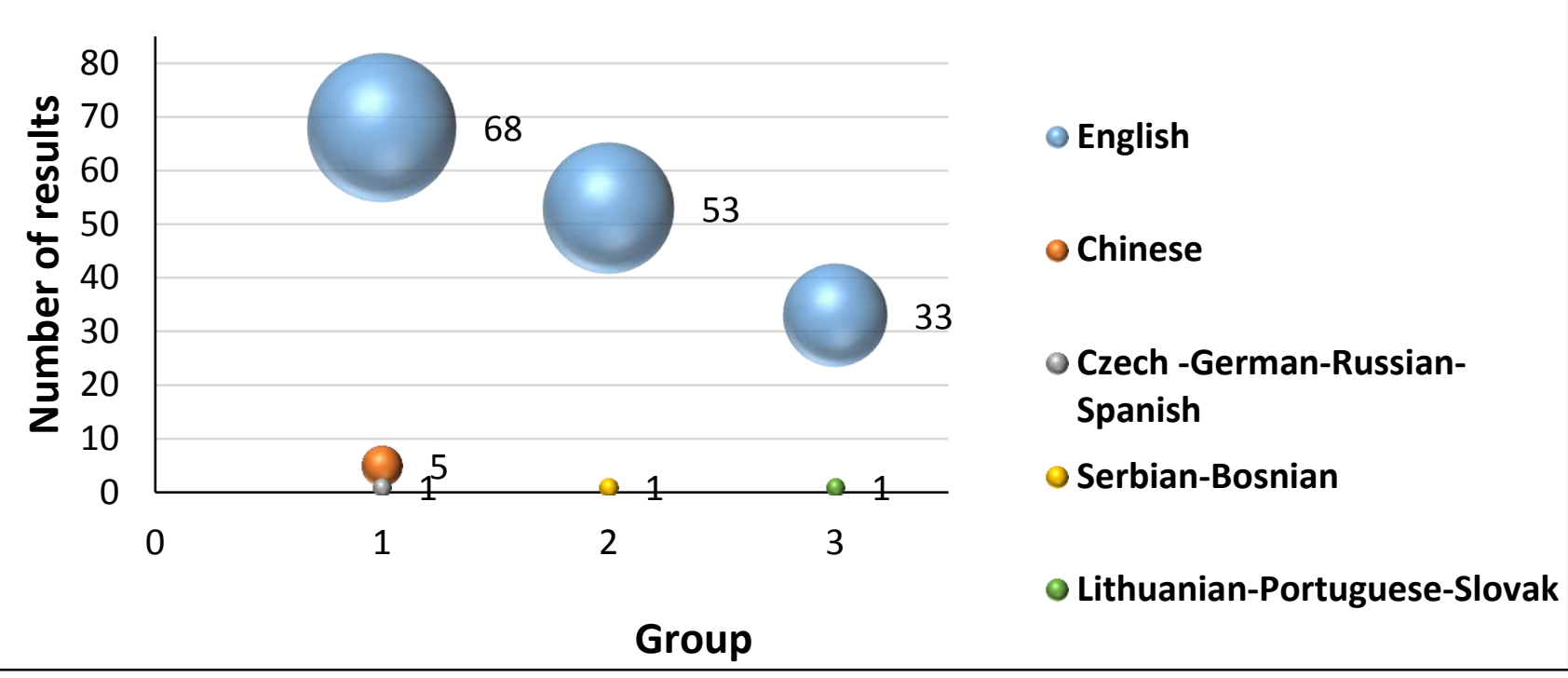

Fig. 2. Literature overview per group studied regarding the language written within the period of analysis 1980's - 2010's.

Regarding the profile of languages in which the literature results were written it was reported that the English-written papers are dominating over the other languages of writing, ensuring the broader possible dissemination of the research outcomes worldwide comparing to other languages of local interest or applicability. The fact of sparse publication at other, non-English, languages it implies that the widely appreciated language of researchers' sharing their knowledge of economic systems, economic development and opportunities of skills' building, it is certainly the English language, Figure 2. In quantitative terms, the calculated R-squared coefficient of determination, $\mathrm{R}^{2}$, it is a measurable indicator of goodness-of-fit of the logarithmic equations derived, Figure 3.

Specifically, $\mathrm{R}^{2}$ values are considered fairly high (more than 0.80) for all groups 1,2,3, which implies a precise representation-fitting of all top- 15 subject areas reported for all groups in the last three decades of literature results. Subsequently, in comparing the thematic "behaviour" among these three groups, it was shown a sharper declining frequency of top-15 subject areas at group 1, followed by flattening plateau trends at groups 2 and 3, respectively. This behaviour implies a relatively stable behaviour regarding those factors determining economic development through knowledge skills and globalization opportunities (groups 2 and 3), comparing to highly unstable and rapidly evolved dynamics of interpreting modeling dynamics of economic systems (group 1), Figure 3 and Table 1.

Since in all cases the "a" equation constants, -10.69 , -9.006 , and -5.642 , are less than 1 , the relevant lines are all representing logarithmic decay functions. However, a selection of top-10, out of top-15, subject areas was made due to comparability reasons, since there were only 10 common subject areas reported among all three groups studied. Their descending order has been graphically represented at Figure 4 . 


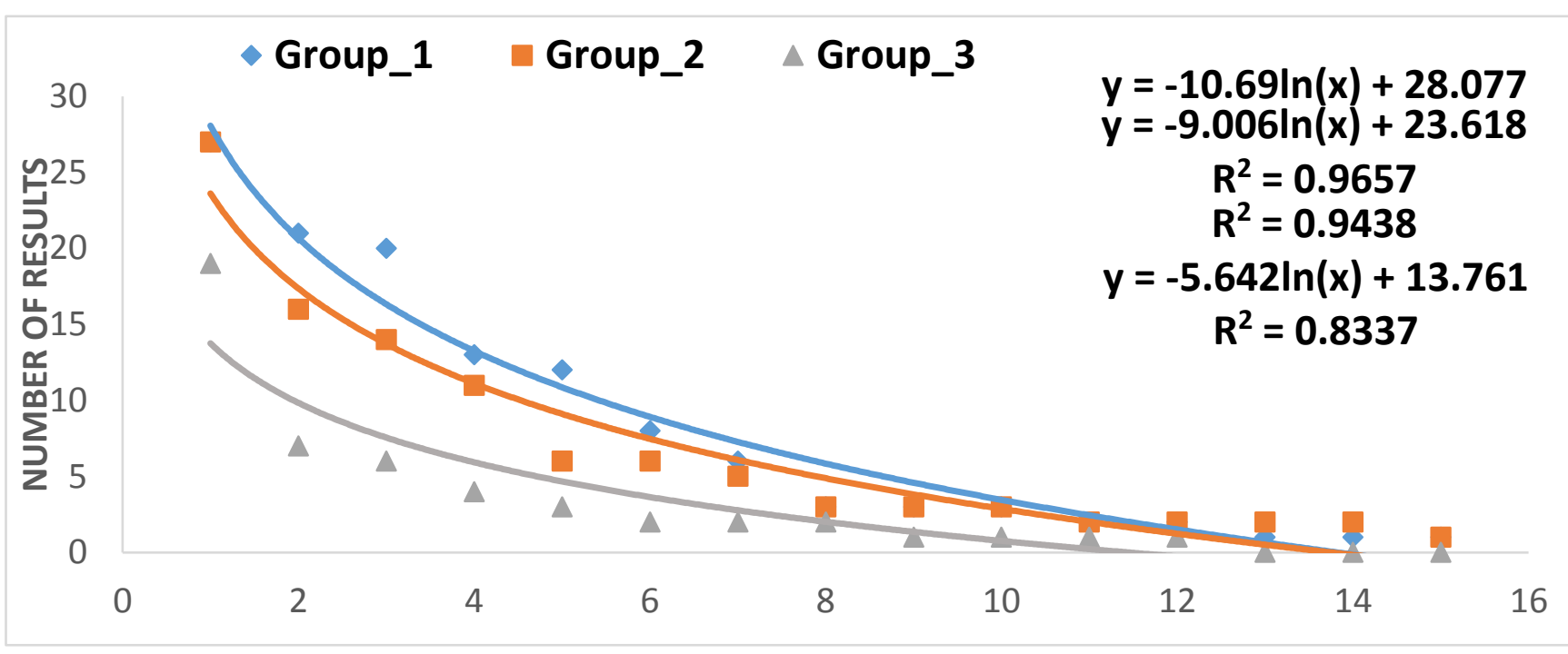

TOP-15 SUBJECT AREAS

Fig. 3. Top-15 of subject areas in descending order of results reported for the period 1980's - 2010's.

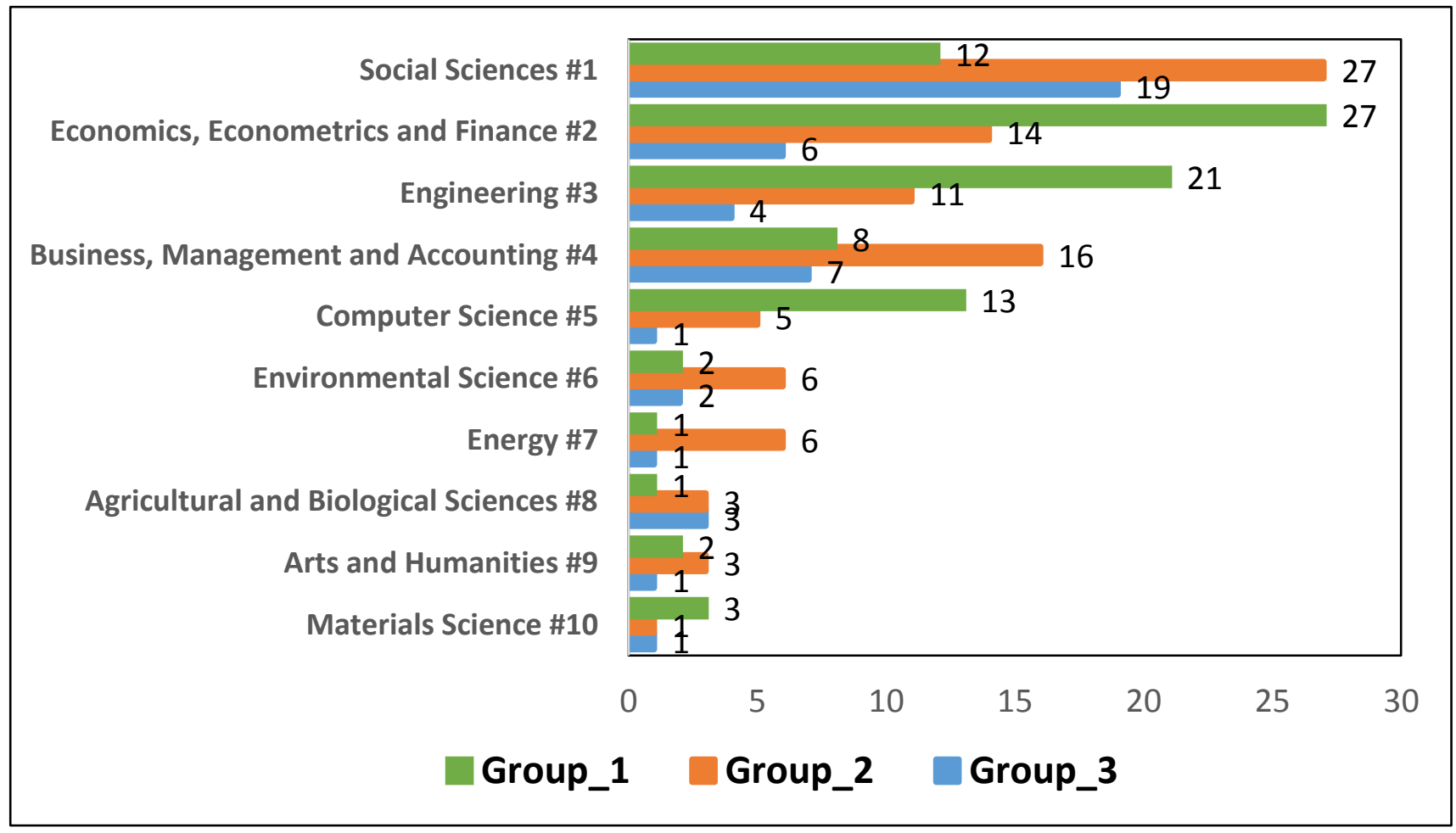

Fig. 4. Graphical representation of Top-10 subject areas of results reported for the period 1980's - 2010's.

The graphical representation of top- 15 of countries proved, by trial and error, the best $\mathrm{R}^{2}$ values all reported at exponential decay functions, neither logarithmic nor linear. These exponential profiles of literature results in descending orders per group they are referring to the period of 1980's - present, Figures 5 and 6. It was noted that the initial values of: $11.282,7.599,4.5217$ of all exponential functions (that are y-extrapolate intercepting) they are related to change-factor (e-power value) less than 1 , that is why the "decay-declining" behaviour was reported.
This behaviour implied a relatively stable and flatten behaviour on determining economic development through knowledge skills and globalization opportunities (groups 2 and 3) comparing to results in group 1, where a striking, unstable, and rapidly evolving literature production has devoted to investigate the models utility in interpreting the dynamics of economic systems, Figures 5, 6, and Table 1 . 


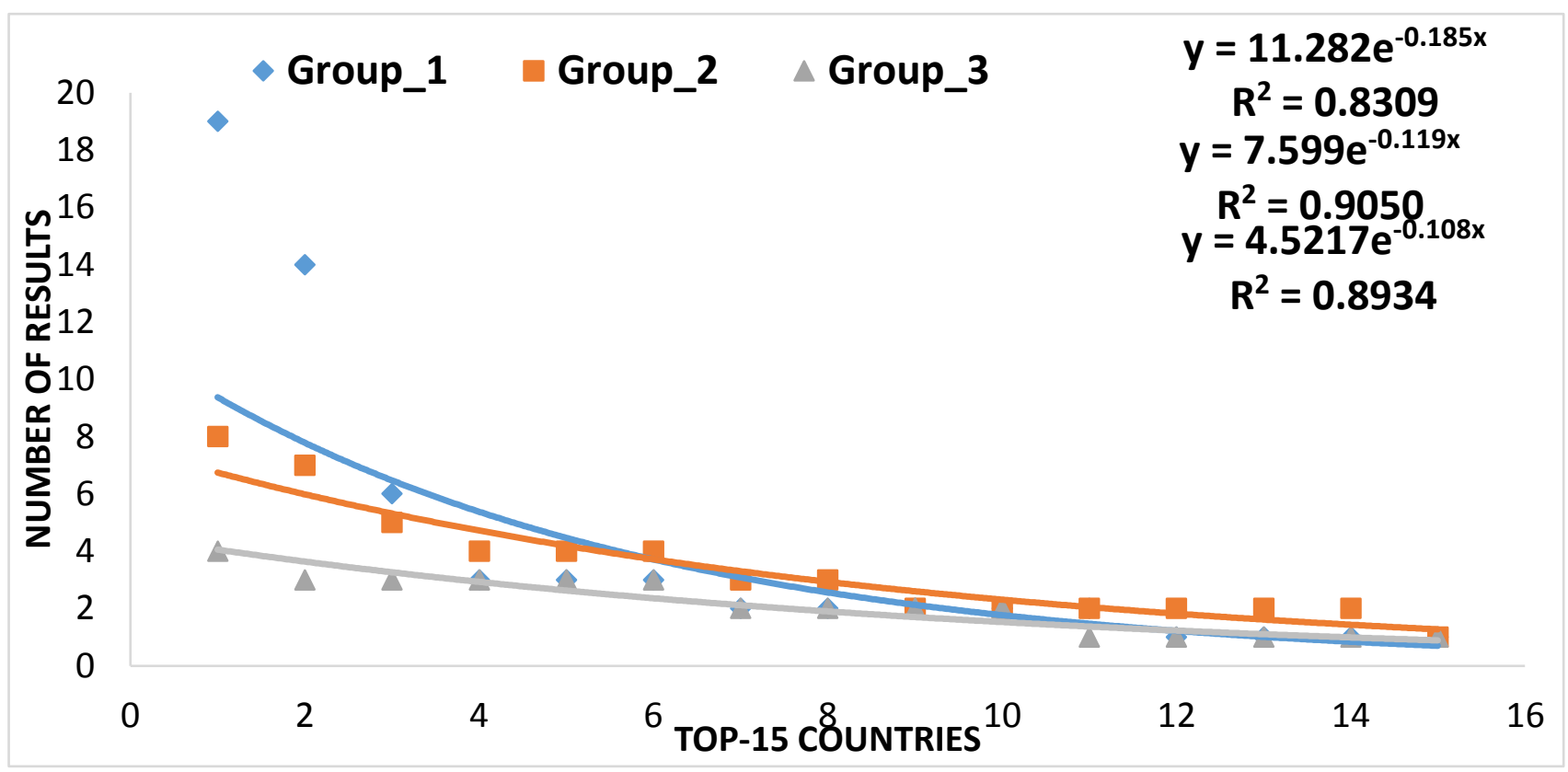

Fig. 5. Top-15 of countries in descending order of results reported within the period 1980's - 2010's.

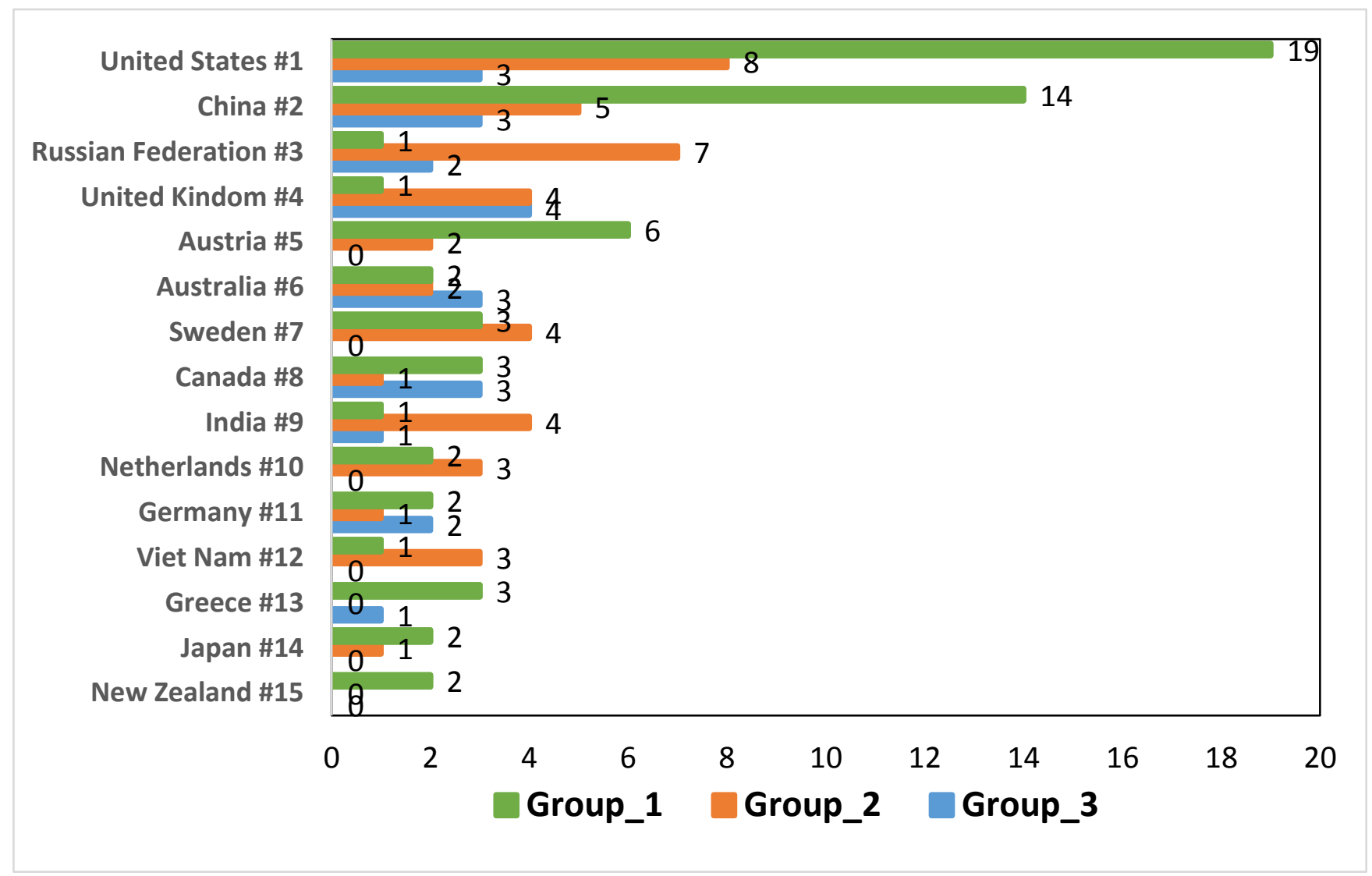

Fig. 6. Graphical representation of Top-15 countries of results reported within the period 1980's - 2010's. 


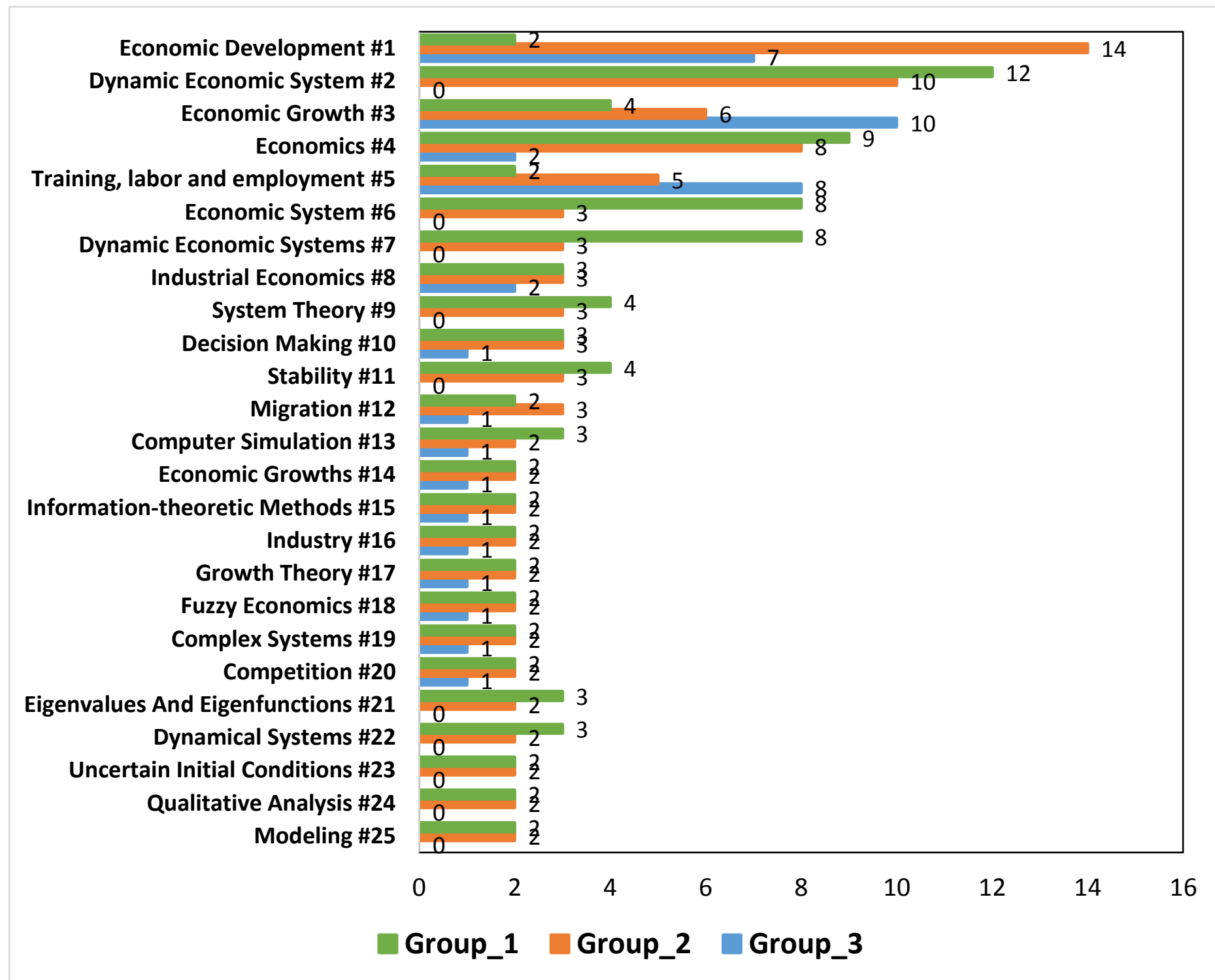

Figure 7. Top-25 of keywords in descending order of results reported within the period 1980's - 2010's. 


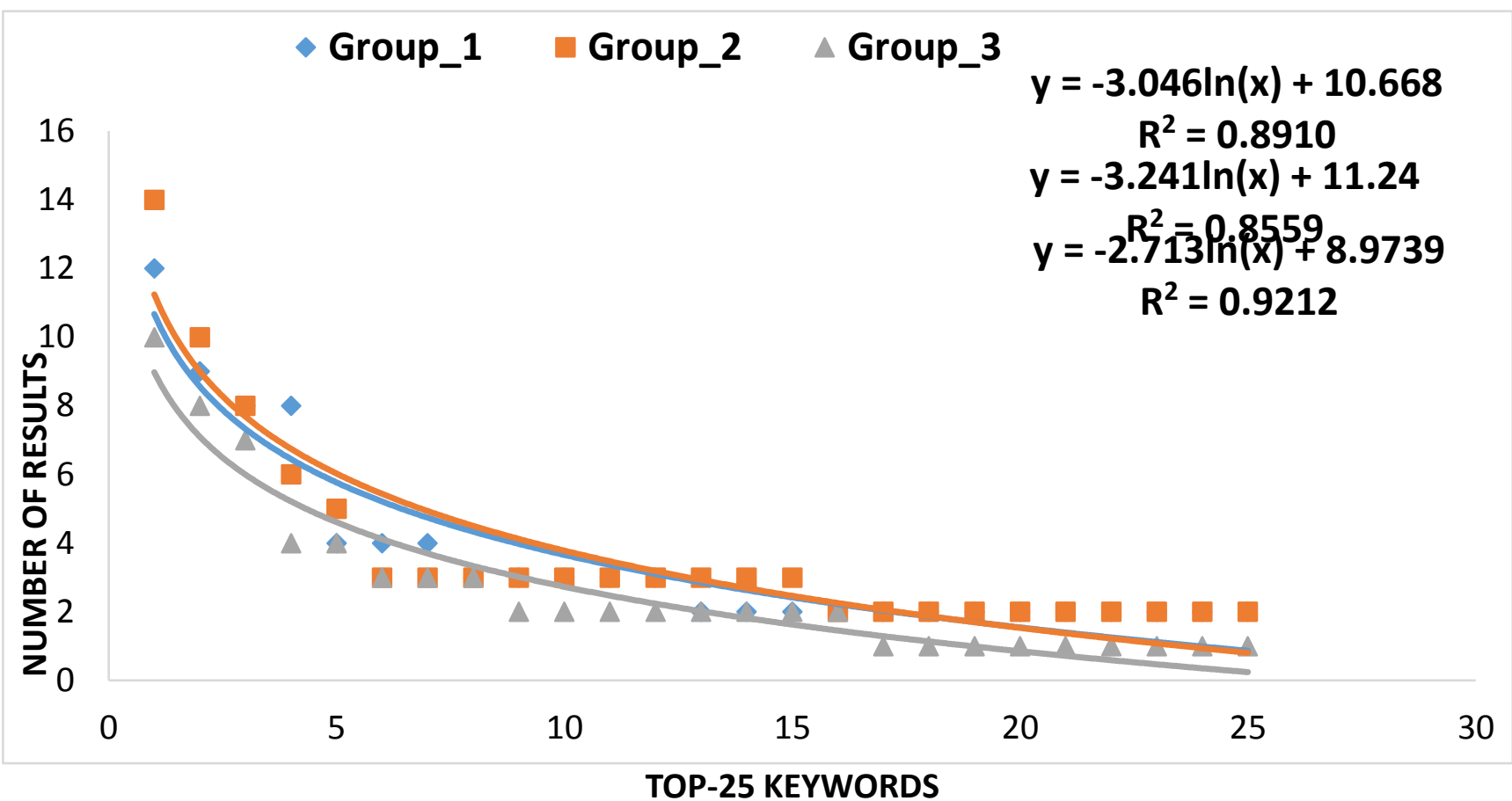

The graphical representation of top-25 keywords proved, by trial and error, the best $\mathrm{R}^{2}$ values all reported at logarithmic decay functions, neither exponential nor linear. However, the derived mathematical (logarithmic) equations revealed two significant findings comparing to the preceding toprankings results, per subject areas and countries, respectively. First, the coefficients of all groups were calculated as relatively similar to each other: -3.046 , -3.241 , and -2.713 , implying a relative thematic endurance and chronological stability of research objectives in studying dynamic economic systems and economic development issues, especially in the light of knowledge, skills, and globalization, Figure 7.
Second, while it sounds organizationally heterogeneous the attempt to find common keywords for the differentiating (to each other) structured groups 1, 2, 3, it was noteworthy that the Scopus search yielded exact 25 identical keywords that were reported for at least two (out of three) or all three groups studied. This finding also implied throughout earlier and recent research studies that have been published at all three groups 1, 2, 3, a relatively stable methodological basis of conducting analyses and future development has been literature-shaped throughout the referencing period 1980's - present (partial coincidence among three trendlines of Figure $8)$.

Figure 8. Graphical representation of Top- 25 keywords of results reported in descending order per group studied within the period of analysis 1980's - 2010's.

At Table 1 all mathematical variables referring to trend-lines and equation parameters they have been collectively represented. It can be signified that the top-list expansion from 15 registrations (in the fields of "subject areas" and "countries") towards 25 registrations (that it the field of "keywords") resulted in graphical homogeneity among the trend-lines of groups 1, 2, 3, in the field of "keywords". This finding implies a relatively stable basis of conceptualizing and organizing the terms and the domains of future research development of the three groups and the five fields examined. This converging behaviour should also support better methodological synergies to be developed, while thematic opening to future fields it should be anticipated under the given specifications of literature, Table 1.

Table 1. Overview profile and mathematical interpretation of top-referred fields of analysis: subject areas, countries, keywords.

\begin{tabular}{|c|c|c|c|c|}
\hline Parameter & $\begin{array}{c}\text { Type of } \\
\text { mathematical } \\
\text { equation }\end{array}$ & Group & Coefficient/Factor & $\mathbf{R}^{\mathbf{2}}$ value \\
\hline Top-15 subject & Logarithmic & 1 & -10.69 & 0.9657 \\
\hline
\end{tabular}




\begin{tabular}{|c|c|c|c|c|}
\hline \multirow{4}{*}{ areas } & Logarithmic & 2 & -9.006 & 0.9438 \\
\cline { 2 - 5 } & Logarithmic & 3 & -5.642 & 0.8337 \\
\hline \multirow{2}{*}{$\begin{array}{c}\text { Top-15 } \\
\text { countries }\end{array}$} & Exponential & 1 & 11.282 & 0.8309 \\
\cline { 2 - 5 } & Exponential & 2 & 7.599 & 0.9050 \\
\cline { 2 - 5 } & Exponential & 3 & 4.5217 & 0.8934 \\
\hline \multirow{2}{*}{$\begin{array}{c}\text { Top-25 } \\
\text { keywords }\end{array}$} & Logarithmic & 1 & -3.046 & 0.8910 \\
\cline { 2 - 5 } & Logarithmic & 2 & -3.241 & 0.8559 \\
\cline { 2 - 5 } & Logarithmic & 3 & -2.713 & 0.9212 \\
\hline
\end{tabular}

\subsection{Technology domain}

One of the main technological challenges for research is the integration of renewable energy sources in the electricity grid, where the development of large-scale energy storage systems have to overcome their intermittency. Therefore, among the relevant research domains it is the development of a novel application of such energy storage system by exploring its potential integration of national electricity markets, such as in Spain, under technical constraints [11].

In another energy-based technology the concept of CHEST (Compressed Heat Energy STorage) was introduced as a promising system in which the excess electricity can be utilized to increase the temperature of a heat source by exploiting a high-temperature heat pump. Such a CHEST system it is a detailed dynamic model that was applied at a 26-MW wind power plant in Spain. Different capacities of the storage system were assessed and the quantitative analysis resulted in roundtrip efficiencies above 90\% achieved at all simulated scenarios, while the CHEST system can produce a range between $1 \%$ and $20 \%$ of the total energy contribution of the power plant, depending on its size. Moreover, the CHEST concept could be economically feasible if its capital expenditure (CAPEX) ranges between 200 and 650 $\mathrm{k} € / \mathrm{MW}$ [11]. From a technical point of view this heat can be stored in a combination of latent and sensible heat storage systems. Subsequently, the stored heat can drive an organic Rankine cycle, thus, supporting electricity production when needed [11].

It is also noteworthy the application of a system dynamic model (SDM) for drilling and blasting operations as an interactive system. In particular, drilling and blasting are considered as the most significant operations in open pit mines that play a crucial role in downstream stages. Earlier researches had optimized these operations as two separate parts under specific parameters, while jointly addressing the technical and economic uncertainties such as rock density, uniaxial compressive strength, bit life and operating costs, for different optimization conditions. Similarly the Vensim simulation software was proven a powerful dynamic tool for both modelling and optimization under deterministic and uncertain conditions. This argumentation is actually dependent on the uncertainties that are considered at modeling [12].

\subsection{Environment - Ecology domain}

The complexity of ecological-economic systems is significantly reducing researchers' ability to investigate systems' behavior and to propose targeted environmental and/or economic policies. Following recent suggestions of integrating nonlinear dynamic input-output (IO) modeling, Uehara et al. [13] developed a fully dynamic ecological-economic model by integrating IO with system dynamics (SD) for better capturing critical attributes of ecologicaleconomic systems. The modeling technique, dynamics and scenarios allowed the exploration of trade-offs between economic and ecological outcomes and the evaluation of restoration impacting on water quality improvement for fisheries population [13]. Besides, the development and the evaluation of various scenarios can be accomplished through policy-impacting sensitivity analyses. In this respect the model should be applied to the degradation of fish nursery habitats by industrial harbors in the Seine estuary, France [13].

Another study of environmental interest impacting on future climate and socio-economic change on the flow and nitrogen fluxes, it was conducted for the Ganga river system [14]. This was the first basinscale water quality study for the Ganga considering 
climate change at $25 \mathrm{~km}$ resolution together with socio-economic scenarios. At this analysis the revised dynamic, process-based INCA model, it was used to simulate hydrology and water quality within the complex multi-branched river basins [14]. All utilized climate realizations predicted temperature and rainfall increases' forecasting by the 2050s with significant increase by the 2090s. These changes also generated increases in monsoon flows and increased availability of water for groundwater recharge and irrigation, but also more frequent flooding. In parallel, decreased concentrations of nitrate and ammonia were reported due to increased dilution [14]. Different future socio-economic scenarios sustained a significant impact on water quality at the downstream end of the Ganga river system. It is notable a less sustainable future regarding the deterioration of water quality due to the sociodemographic pressures from higher population growth, land use change, increased sewage treatment discharges, enhanced atmospheric nitrogen deposition, and water abstraction. Contrarily, water quality was found to improve under a more sustainable strategy, as envisaged in water sources of localized interest, as in an anticipated Ganga cleanup plan [14].

At another study the economic evaluation of ecological restoration projects involved a risk analysis process, in which a system dynamics model was constructed for eight diverse case study sites where ecological restoration was pursued [5]. From an economic point of view it was stressed out that restoration costs were certainly varying across each one of these ecologically-sensitive sites, as did the benefits associated with restored ecosystem functioning. The system dynamics model could simulate the ecological, hydrological and economic benefits of ecological restoration, while informing a portfolio mapping exercise where payoffs were matched against a number of other factors, including measurable indicators of project costs and risks involved [5]. This was the first known application (at the time of its publication, seven years ago) that linked ecological restoration with system dynamics and portfolio mapping. Subsequently, such an enviro-economic approach was able to (early) move beyond traditional indicators of project success, since the effect of discounting was actually eliminated. Moreover, it was shown that dynamic modelling systems with portfolio mapping can support decisions whenever markets for restoration activities are proven feasible [5].

\subsection{Socio-Economics domain}

From a socio-economics point of view it is crucial to denote that relevant researches have focused on creating models of economic market on specific geographic background areas using system dynamics principles, either new or being attested by previous model(s). In such an approach a model can be characterized by particularities related to the area, taken into consideration key-associations among national economic contexts, geographical areas, and their enterprises. In such a study Dumitrache et al. [1] investigated the development of such modelling at the Romanian context, while the development of such modeling represented a new implementation of a (formerly) background model [1].

The today fast evolving global economy revealed contentious issues that emphasize on labor migration. These issues are considered among the major factors supporting the development of the labor market. Besides, local inflow of migrants should correspond to the labor resources demand of these local labor markets. Therefore, among the key-aspects of such a socio-economic transition is the estimation of migration flows between countries with different levels of socio-economic development [15]. According to this socio-economic context it is noteworthy the development of models to better describe the impact of labor migration on economic systems among countries of migration attraction, as proposed by [15]. These authors elaborated a dynamic multi-factor model based on the assumptions of the positional games theory, enabling the behaviour prediction of each individual based on economic factors. The model was conceptualized on the basis that potential migrants have rational information on the differences of living and working conditions in both countries of origin and migration attraction. Such a model takes into account several economic theories of migration in order to better investigate the migrants' behavior in terms of migration barriers' absence. This modeling target is the migration impact assessment on the development of socio-economic systems for countries of migration attraction using an approach that was based on the Cobb-Douglas production function [15].

At another socio-economic context a model was designed according to the key-factors of the todayreported economic development in Russian Federation. In particular, the socio-economic analysis was applied to assess the impact of the identified factors on quantitative and qualitative indicators of the development of the Russian Federation [2]. It can also signify the role of national economy dynamic properties in order to achieve 
structural innovations for dynamic harmonization and economic growth [2].

Similarly, Shao et al. [16] established three models of dynamic input-out economic systems with multiple delays. Uncommonly, the systems were developed under singular capital coefficient matrices which are a common practice at economic models. By equivalent transformation, the economic models were developed as three discrete-time singular systems with multiple delays, while three admissibility conditions were deployed and expressed in terms of linear matrix inequalities (LMIs) by the Lyapunov approach [16].

\section{Methods and analysis}

\subsection{Globalization, knowledge acquisition and economic development}

During the last three decades, the determination of the HRD/training functions within organizations is an imperative and complex issue. Iatagan et al. [17] signified the role of education, scientific research, continuous training, and qualified human capital in order to activate knowledge and individual competences, while moderating the unemployment and poverty rates, confronting political and socioeconomic crises under globalization, and improving the quality of human resources among the developed European countries [17]. Besides, the role of investment in secondary education has been proven more beneficial to income and profit, comparing to investments in tertiary education and trading organizations [17]. On the other hand, limitations against the effective transition from secondary education to the labour market are the demotivation for learning of unemployed people, lack of opportunities for adolescents in rural areas, high rates of drop out of school, demographic loss, disrespect to teachers, transportation obstacles, the costs of higher education, the restricted private training opportunities, as well as uncertainties in finding a job after graduating [17].

In parallel, professional training and supportiveness to vocational guidance are valued as invaluable investments that foster higher productivity of the employees, enabling them to be flexible at continuously structural, technological and radical changes that occur throughout their lifetime [17]. Organizations should appreciate educated employees in terms of entrepreneurship, flexibility in training, lifelong learning, professional re-qualification (possibly on a state's expense), professional continuous formation, exceptional competences in learning and establishing social relationships [17]. In a wider organizational context, societies necessitate and encourage the social cohesion and work promotion, active citizenship, professional and personal fulfillment, adaptability to working conditions, enhanced mobility, and last-longing employment, while relevant national, political, and legislative reforms are proven competitive, tolerant, and democratic [17].

It is also noteworthy that during the last three decades researches have been focused on the transformation from industrial-based and oil-based types of economy towards a knowledge-based economy [18,19]. This transformation can be associated with the general framework of strategic management, linking HRD/training functions with intellectual capital (IC) [18], innovation, information and communications technology (ICT), national economies, education and employment [19]. These linkages are more pronounced for profit organizations (contrarily to public and non-profit organizations) even though the latter are proven as important agents in politics, economics and welfare systems among developed and developing countries [18]. It has been also reported that national programs can stress out the importance of diversifying the economy through development of the knowledge economy, thus, supporting policymakers to create a sustainable knowledge economy framework at national levels of analysis [19]. In the relevant literature Italian NPOs should be characterized as action-oriented and self-referral rather than knowledge-based, thus, intellectual capital can effectively overcome the gaps in strategic management of HR at these NPOs, in comparison to training functions [18].

In a HR-focused management it has been denoted that HR systems, in general [20], and training systems, in particular, play a determining role of operating more ethical organizations than ever before [21]. These findings shed light on the efficacy of specific ethics training programs that should be designed, implemented, and monitored as systems, thus, a systemic approach for effective training systems is the simultaneous consideration of needs (implying problems to be solved), inputs (including the trainees' characteristics), process (the pedagogy side), and output (referring to attitudinal and/or behavioural changes) [20]. 
Valle et. al. [22] indicated that companies commonly adopt training strategies where emphasis is based on enhancement of individual specialized skills that aim to productivity improvement [22,23]. Contrarily, companies that use work processes as repetitive and routine tasks, de-emphasize this type of training and are typical of "cost" and "extract profit" (emphasizing on individuals' training) strategies, involving dynamic growth and company turnaround/recovery strategies; the latter are accomplished through groups' cooperation and results [22]. This contingent approach manipulates training as a means of skills and expertise provision in the future under innovation strategies. It is also denoted that limited level of contingencies exist between training policies and business strategy, especially when time dimension is also accounted for. The findings of Valle et. al. [22] showed a relatively complex interrelation between HRD training with effectiveness of company strategies [22]. Conclusively, key-aspects of HRD and training are that of explaining differences in HRM practices, adoption of a wide spectrum of internal factors, including the size of a company, its history and traditions, organization structure, technology usedas well as the external factors that apply at national economies and their industrial sectors, respectively [22].

In another similar study a holistic approach has been reported regarding social skills in alignment with spending of physical capital, innovations' involvement, worker-management relations, legal framework for trade unions, alteration the cost of labour management, lower wages, unemployment, monitoring technology, and workers' motivation; being more pronounced among industrialized and developed economies such as in Japan [24]. Furthermore, a managerial distinction between primary and secondary labour markets revealed that primary sector unemployment was lower since these jobs involved higher levels of commitment, whereas the secondary sector jobs were less satisfying, having less training; being subject to relatively high levels of monitoring and turnovers, comparing to the primary sector jobs [24]. This approach of endogenous worker commitment makes a distinct difference to labour management function, linking social skills with human resource policies [24,25].

At this point it is noteworthy that HRD and training functions are characterized by complexity between both their internal design of operation as well as within their surrounding entrepreneurial environment. HRD is directly related to both specific economic downturn and to wider holistic functions within organizational strategies [26]. The need of evaluating "HRD", "training policies", "output", "quality of product", "levels of waste" it is straightforward, whereas the forms of evaluating training effectiveness it is less obvious, since a simple good returns on investment in HRD and training are not positively interrelated. In parallel, the training function follows either a) formal processes in performance management at large and multinational companies, including re-design, training function audit, content re-orientation, or b) less formal processes without performance management schemes; the latter are mainly reported at Small and Medium Enterprises (SMEs).

In this multi-parametric context it is notable to investigate HRD and training policies under companies in crisis, since many companies have experienced a crisis in the past mainly due to external environment, i.e., the market's economic and political development [26]. In this respect everything should be examined concerning the human factor, implying that half (under crisis conditions') companies they had prepared a crisis scenario, and they handled the crisis with an internal crisis team. In parallel, crisis communication should become more effective while focusing on specific personnel measures. Austerity measures should apply in the area of HRD at a time when the company is in crisis. Measures of particular interest that can be proposed and recommended can make the whole process more efficient. Such measures should not be massive, but the companies can well set up personnel processes such as short-term limitation of variable wage components and other benefits [26]. An enterprise does not have to lose its attractiveness or level because employees do not restrict their basic wage income. Employees will confirm that the company acts reasonably with them and does not hide anything from them. Contrarily, it is also critical a good-intending communication management to be developed with their employees, enabling an honest understanding of this situation [26]. In such an approach HRD signifies that its functionality and evaluation should reinforce the establishment of organizations' profile, since the results of evaluation can be proven a powerful marketable tool for training, being based on the following domains:

-The financial terms, which validate the achievement of the laid down objectives. 
-The social terms, which evaluate the overall costbenefit of the all courses that are involved in the $\mathrm{HRD} /$ training programs.

- "Apprenticeship" that should be considered while focusing on cost reduction and minimization of the employee's training time [27].

-Ethical arguments that can be investigated into the following integrative framework for ethical development and HRD and training topics [20].

-At an operational level training can be thoroughly organized and delivered. Whenever training is considered as a corporate strategic function, all levels within the organization have a participation role. Therefore, consistency and coherence in training policy should be valued at a corporate level in which training function needs its own evaluation processes to be established.

\subsection{Globalization and labour mobility}

The term of "globalization" is related to international trade and investment, being widely used to incorporate a wide spectrum of activities: development, economic bloom, delightful consumers, as well as a range of political and economic initiatives among nations that support the establishment of social, cultural and technical advancements in science and philosophy. It is noteworthy that the dominant feature of "globalization" is its human-anthropocentric attribute that determines the balance between human-tohuman interactions and reflects the wider and unequal international relationships between states. It is also widely accepted that the rich nations sustain the leading role and the historic responsibility of running policies in a globalized world of a liberalized international trade/marketplace. In such a context those rapidly developing economies, such as China, should make larger contributions to the increase in human knowledge by holding science and technology power. In this respect it should be advocated scientific culture as a lifestyle, taking it as the most significant component of advanced socialist culture and the foundation of a science and technology power [28].

During the beginning of the $20^{\text {th }}$ century globalization has accomplished a conceptual and operation expansion from intra-national trade towards the engagement of powerful multinational companies. These companies exhibited an impressive number of organizational and technological innovations that expanded the products and services offered by a concentrated capital and productivity. Such concentrated productivity has been shaped by a new type of industrial workforce who made their income exclusively from the relevant factory system of production. In this transitional phenomenon of globalization the liberalized international trade stimulated the opening of populous countries, such as China and India, to steadily scale-up their exporting trade and support the flow of foreign capital by producing basic commodities at affordable prices in order to ensure their smooth diffusion to the local markets. In parallel, political planning motivated trade deregulation, markets' expansion, as well as improved wages, workfares, or working conditions.

Such historical milestones ended the European colonialism, the end of the Cold War, and the state communism as opponents to the capitalist system, followed by the foundation of the World Trade Organization in 1995, the China incorporation into the global economy arena and the EU eastward expansion. In particular, a positively apparent impact and a gross domestic product (GDP) steady growth were reported by the EU enlargement, being more apparent from 2007 when the new EU member states were admitted into the Schengen zone. Over the entire 2004-2012 period, GDP per capita of the EU8 was increased by about 2313 USD annually on average relative to the synthetic EU-8 [29].

The interrelation between "globalization" and "workplace patterns" is crucial and it should be determined by a complex grid of time, place, pace, technical, cultural and social modes [30]. Such working conditions are framed, on the one hand, by routine and low-skills tasks that are prevailing across nations and industries and, on the other hand, highly novel and technically specialized working positions are gradually needed among developing and developed economies. Therefore, "globalization" reflects an accelerating pace of high-speed information networks that advances a homogeneous and standardized "cultural imperialism" that levels down to a bland uniformity commercial transactions, global culture and traditional values, whatever skillful, or not, the workforce may be educated. It is apparent that this "economic globalization" fosters "cultural homogenization" where the national economies are encouraging the integration into a single global system that "sorbs" the differentiation, "deprives" individual nations from localized control and "degrade" autonomous political administration. On nation-states' side they should reduce "protectionism" and promote industry and jobs, offering companies and investors' flexibility to 
invest in skills and infrastructure. In this globalization context employers are putting effort and capabilities to effectively and efficiently organize their work, even though these internationaloriented policies should "expose" high-skilled workers to routine, low-paid and low-skill manual production work, while no attractive opportunities of personal development and employment rewards are offered to low-skilled workers, likewise. In this socio-economic and cultural environment policy makers are responsible to consider: a) the inevitable role of imposing unpopular policies that form an odious political profile and b) the fact that global economy is the systematic result of policy decisions at national and international levels, which also determine the mobility of industrial-production and labour-expertise. In a national-related context, global trends of liberalization of working life, increased labor migration, the platform-running economies, reduced unionization, more precarious work, they all challenge the working life model among highly industrialized economies of North Europe and the reliance on standard working contracts. Such a trend may result in increased inequity, reduction in generalized trust, and even poorer public health conditions. Politicians and other stakeholders in these developed countries should cope appropriately with globalization and technological changes so these countries can uphold their well-organized working life and good societal achievements [31].

\subsection{Learning skills and working opportunities for migrants}

Migration is a complex and worldwide-spread phenomenon. This complexity resides to the fact that migrants are persons who are equipped with skills and pursue relevant career jobs, while aspiring the humanitarian needs of belonging, team working, and rewarding. However, the hosting countries do not always offer attractive remuneration packages to all immigrants for jobs offered, since no all countries do suffer from shortages of workers to low-skilled jobs. Actually the COVID-19 pandemic, the global economic recession, and the Brexit, are typical paradigms of how deep and intense consequences of shortage of low-skilled workers may impact on even robust economies founded among highly industrialized countries, while the foundation pillars of European unification, namely solidarity and democracy, are under serious threat. The ongoing scientific advancements and the intensive spur of technological changes globally, even the technology diffusion within developing countries, they all necessitate not only the employment of semi- and high-skilled workers but also low-skilled workers in developed countries [32]. Indeed, low-skilled workers composite the vital backbone of any contemporary business, especially in servicing, healthcare, transportation, logistics, and ware-house sectors, thus, supporting the calm and the stability of the local communities.

Changing the nature of work it is also related to global recession and job losses, being generated by an uneven global competition on different sessions of the labour market. Therefore, workers' mobility should be considered as inseparable phenomenon of global competition among governments to survive or to make profits in an international marketplace. It is commonly known that developed countries are strategically and advantageously affectionate to the market competition in various manufacturing products and ways of economy, by continually controlling the balance of the competitors' market shares. Such an example is the unified global labour market of T-shirts production, since near-identical products can be produced at low price by employing cheaper labour in developing countries and reserving the local-social acceptability and social cohesion among the citizens. Therefore, skills and opportunities for migrant men and women constitute the foremost source of wealth generation in knowledge economies that adopt education, specifications, creativity and independent thought for their prosperity.

Nevertheless, it is not comprehensive that immigration is, indeed, a solution to workers' shortage in low-skilled jobs since their mobility should be reported only at multinational companies in UK, US, German, and other developed economies. Indeed, these western and highly industrialized economies offer a wide spectrum of improvements and opportunities to motivate immigrants and to ensure a way of living beyond the subsistence level while working abroad. However, there are cases where income offers barely more than subsistence, thus, "trickling-down" into the local economy. From the entrepreneurial side, businesses can be organized in different ways than work moving to cheap labour. It is indicatively noted that under the global structure of outsourcing services labour can be brought to the job, enabling prefabricated components that are produced overseas and all its technically-advanced tasks to be completed by native, high-skilled workers; seldom there are also jobs completely immune to competition. It has been stressed out that the increasing trend for prefabricated components can be now turned into numerous applications as they 
support a much faster output for the ever increasing urban construction demand. Moreover, adopting prefabrication technology promotes mechanization in the manufacturing sector and creates new areas of employment, driven by the positive effect of prefabrication technology on the profitability and the whole work cycle [33].

Subsequently, routine production of standardized goods can be made everywhere under the precondition of adequate labour supply and infrastructure, expanding the engagement of lowskilled workers and their competition at routine production far beyond the narrow national borders. The aforementioned it is a "value chain" phenomenon in which high-tech manufacturing products are fabricated and modulated at developing countries and they result in moderating, or even downsizing, existing market share from traditionally developed, but also in fast emerging developing, economies of Europe the US, Asia (mainly in China) and America (both North and South America). A delayed economic restart is caused by the growing propagation and different reaction to the pandemic that would effectively delay the full resumption in both Europe and the US, despite the projected recovery from China. This delay may be primarily caused by market vulnerabilities (e.g. trade tensions, declining sales) that are likely to persist even after a full Chinese recovery, given the tight inventories (fewer than six weeks) and complex supply-chains [34]. The schematic representation of the importance of education ("Education" line) across developing and developed countries has been depicted at Figure 9.

\section{Education}

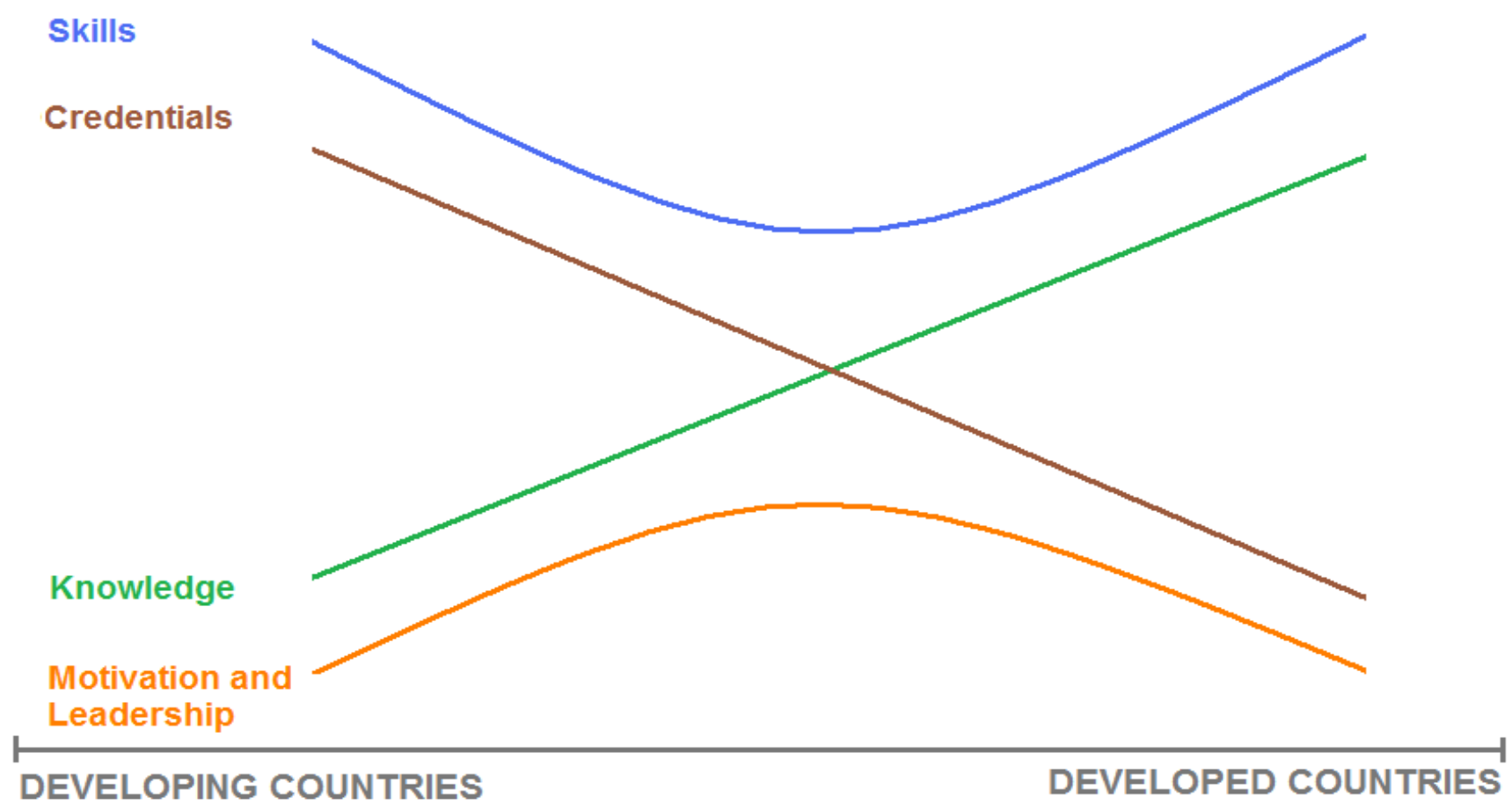

Fig. 9. The contributing factors of workers' behaviour and priorities in an entrepreneurial environment. Source: Modified and enhanced from [35], p. 49.

At Figure 9 the "Education" is considered as the dependent variable, while the four compositional (independent) variables embodied in education are that of: a) Credentials ("Credentials" line), b)
Knowledge ("Knowledge" line), c) Skills ("Skills" line), d) "Motivation and Leadership" ("Motivation and Leadership" line). In particular, it has been proven that at all levels of development, the importance of education for adult income is 
approximately the same, the "Education" line. However, the compositional breakdown of the independent variables of education it is systematically varied by the level of national development. In developing countries the credential embodied in education is relatively more important for determining workers' income (the "Credentials" line) whereas in developed countries the knowledge embodied in education is relatively more important (the "Knowledge" line).

Moreover, based on Figure 9, it has shown that skills' acquisition in developing and developed countries it is considered an important variable, but the relevant trend-line has shown a downward behaviour in middle-developed countries and then an upward trend, shaping a low-valley and flattening behaviour. This behaviour is explained by the fact that workers are not willing to begin working for positions in countries of moderate, or similar to their familycountries, rewards' offering (left-side downward slope of the "Skills" line). Therefore, these countries are considered as an intermediate arrival for highskilled workers to immigrate and finally work at their final destinations-hosting countries (right-side upward slope of "Skills" line). Besides, "Motivation and Leadership" is considered a less-important variable in all developing and developed countries. However, the relevant trend-line has shown an upward behaviour in middle-developed countries, shaping high-peak behaviour. This high-peak behaviour can be attributed to the fact that while both types of low-skilled and high-skilled workers are shown a bodily and social opposition when ruled to done their work by authoritarian motivational leadership (left- and right- sides of "Motivation and Leadership" line), the democratic and laissez-faire leadership style should be ideally fitting in middledeveloped countries' working environments (centralzone of "Motivation and Leadership" line). According to Figure 1, above, globalization is expected to exacerbate the gap between rich and poor countries in the returns to knowledge. Saying that it can be inferred that globalization creates wider economic opportunities for knowledgeable Europeans than it does for (example) knowledgeable Africans [35]. However, the means of creating economic opportunities in this study they are the skills and the motivational leadership, they are similarly behaved at both types, that of developing and developed, countries.

Another important feature of emerging economies is the thread of differentiating the main educational features' offered and divided into theoretical/social/humanistic schools of education, whereas they have to be considered at a coherent and integrate manner in order to support tangible development of technical education. Such types of education, technical and vocational, they can motivate the growth engine of development, innovation, and prosperity. In the above framework, immigration characteristics are as follows:

-Entrepreneurial level, as the sustainable use of materials and services from whichever country that should ensure the best mix of price and quality product for particular inputs.

-Economics level, involving the competitive tax incentives, the bidding-down the cost of labour, and the movement of workers as part of a more widespread migration from rural developing towards neighborhood and developed countries, while the large pool of both indigenous and foreign labour should (but not certainly) serve to depress wages [36].

-Political level, where governmental instability, the successive elections and the unreasonably fierce political disputes are causing delays, postpones, or even cancellations of feasible long-term policies to migration, work organization, jobs' facilitation and equalities, as well as the humanitarian treatment of out-of-law immigrants by the hosting countries. It is also noteworthy that urban- and regional- oriented researches are due to regain their progressive reflexes together with broader political concerns about the future of the EU [32].

-National level, being considered as an irreplaceable tool to confront the shortage of workers to fill lowskilled jobs. While all nations aim to enhance their workforce capabilities and competitiveness with the ultimate scope to maximize their profits, central governments policies reflect wider political and socio-economic issues of skills' manipulation, viable opportunities to development, humans' freedom, and social justice for both migrant men and women. In particular, the determining issues of skills and opportunities for migrant men and women among low-industrialized countries, they are related to many high-skilled citizens emigrate alone, while lowskilled indigenous and immigrant workers constitute the basic pillars of its economic profile [37].

-Skills' acquisition is appreciated as an valuable asset only if knowledge can be put to use, since the human capital approach should be conceptualized only by matching skills supply to skills demand [38]. Among high-industrialized countries the productivity is pursued by investing to technology and 
infrastructure, rather than in skills. Contrarily, among low-industrialized countries employers often demand skills that are irrelevant to technological advancements and to scientific specifications, while even these high-level skills should be further subjected to long-term global competition. In a general socio-economic context, it has been reported the technological capability on inward foreign direct investment (FDI) with the moderation of institutional quality. It has been also denoted that the institutional quality of a host country, the government size, and the regulation have shown positive moderation, whereas money accessibility, legal system, and property protection showed negative moderation [38].

\section{Discussion}

The schematic representation of the keydeterminants of economic development in the COVID-19 era (being analyzed in the sections, above) it has been collectively depicted at Figure 10.

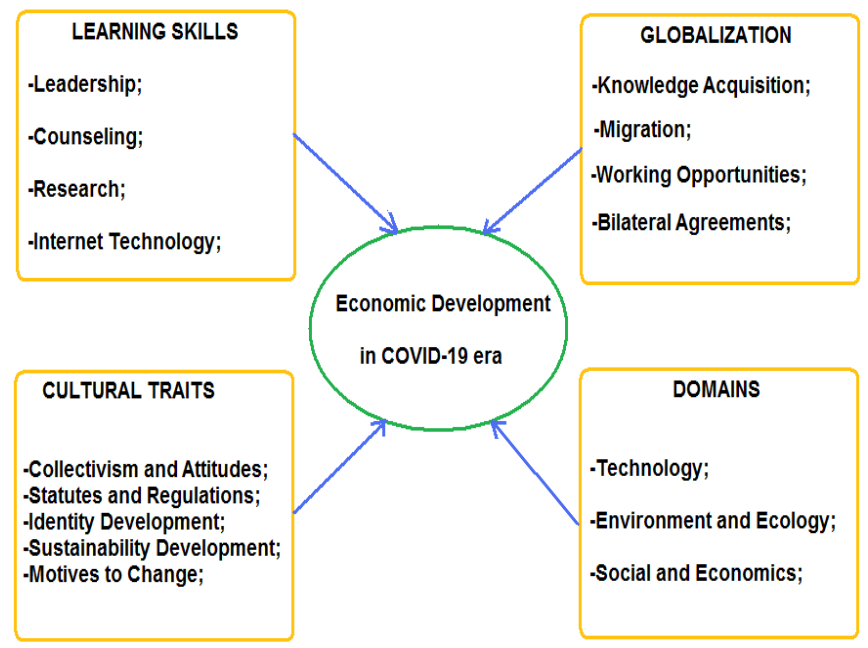

Fig. 10. The research flow-chart of economic development in the COVID-19 era. Source: Modified from [39], Fig. 1.

Based on Figure 10 the relationship between the economic situations and the cloud-based e-learning system (CELS) in the COVID-19 era was proven positive and significant, supporting managers to develop educational and research associations between educational institutions and companies through training courses and research programs. Such synergies can effectively grow the technological infusion in both practical and academic contexts [39].

In a similar study it was denoted that in this COVID19 era of economic recession and the substantial reformation of learning and working modes there should be a shift to increased professional flexibility in future careers, flatter hierarchies and open exchange of knowledge. Furthermore, the recognition of informally acquired skills it is emphasized by experts [10]. In this the transitional and unstable environment the pronounced role of learning technology was signified in order to support a better understanding of these changes and provide facts, solutions and tools to effectively support versatile, focused and personalized learning opportunities [10].

Regarding the widespread inclination of people to be educated by acquiring knowledge and skills, globalization sustains a critical role of achieving both personal development and a wider economic development of contemporary societies. In this context it is noteworthy that globalization is predominately driven by large corporations, industrialized economies and multinational organizations. While enterprises that are operated by petty capitalists may be small, they are substantially significant to the operation of national economies and global markets [40]. Therefore, there is an imperative need a better understanding of petty capitalists' contribution in a global economy, unveiling the potentials, limitations, and challenges of promoting small firms as key-contributors to economic development [40].

Another critical aspect of economic development is whether globalization motivates citizens to be engaged in entrepreneurship at countries of differentiated development. In this context globalization can be associated with the following core perceptions of entrepreneurship: the good opportunities offered to start a business in the local area, as well as the skills and the abilities to start a business, since fear of failure prevents entrepreneurs from starting their business [41]. The authors of this study [41] deployed a combined analysis of individual-level data from the Global Entrepreneurship Monitor (about two million individuals) and country-level data from the KOF Swiss Economic Institute and World Bank (of 103 countries) at the period 2001-2016, concluding that globalization is negatively impacting on the perceived opportunities for entrepreneurship. Contrarily, globalization did not severely change perceived entrepreneurial skills or fear of failure. It was also shown that national economic development is able to moderate the effect of globalization on perceived opportunities. It was also argued the dominant role of globalization in improving entrepreneurship, being partly conditional on eachnation economic development [41]. 
While it is widely recognizable that globalization puts a premium on knowledge, skill formation and development [42], sustainable development [43], trading partnerships and agreements [44], in fact there is no empirical correlation across countries between globalization and returns to education, mainly because education is not everywhere equalperceived with knowledge. The overall contribution of education to income is considered as the joint contribution of two-types of education: education-asknowledge and education-as-credential. The former type dominates in developed countries and the latter type dominates in developing countries. Therefore, while differentiating these two types of education it was shown that globalization can be positively associated with education in developed countries, but it is negatively associated with education in developing countries. Subsequently, it is reasonable to direct the supply and the demand for education according to the level of education, the technological intensification, the governmental initiatives, and the scale of economic development among developed or developing countries worldwide [35].

Indeed, challenges of regional development are the success-cases and shortcomings of specific strategies' adopted to link global and local value chains while moderating regional and social polarization, thus, improving sustainability and self-reliability of learning systems [45]. Learning conditions in the entrepreneurial sector are determined by a plethora of constraining preconditions, such as the limited resources, the personality of trainers and trainees, the market competition, as well as the business environment in which companies are operating [27].

\section{Conclusions}

The versatile and intensively differentiated approaches of globalized inclination acquire

\section{References}

[1] Dumitrache M., Tudor V.C., Mărcută A., Tita V., Sipică A., Popescu D.A., Bold N., Micu M.M., Remodeling and simulation of an economic map system based on system dynamic principles-Case study in southern Romania, Studies in Informatics and Control, Vol. 29, No. 2, 2020, pp. 255-264. DOI: 10.24846/V29I2Y202010.

[2] Korolev V.A., Toroptsev Y.L., Matveeva L.G., Chernova O.A., Modeling of dynamic properties of national economic systems, Serbian Journal of knowledge and skills towards economic development. Utmost important is the phenomenon of traditional immigration features among workers to be engaged at low-skilled jobs that shifts towards semi- and highly- skilled workers who are the fundamental human capital that implements technological changes' spur among developing countries. In parallel, the educational globalization is simplified through the international design and administration of courses from developed countries. Besides, the easiness of intercontinental trips, the advancements in the transportation sector, and the perspective of "knowledge economy", all nurture the migration phenomenon, since it can offer a wide spectrum of employment opportunities for men and women migrants as well as the sense of self-confidence and personal development.

The future trend of learning and working is shaped by intense customization, collaboration and formalization (of informal learning), whereas formal education, skills and training are moving towards more personalized learning strategies in multicultural environments, based on online expert consultations and stronger integration of external learning opportunities. Future researches can be developed in structuring a framework of those cultural characteristics, economic situations, skills and knowledge domains, as well as those sub-criteria that determine these domains, respectively. These "domains" are not common views that apply unanimously to all educational and entrepreneurial contexts, but they are case-specific and exclusively adapted to per-case educational level or system in working environments, accordingly.

Management, Vol. 13, No. 1, 2018, pp. 133-143. DOI: $10.5937 /$ sjm13-12991.

[3] Stakhiv P., Franko Yu., Moskalyk S., Mathematical modeling of complex dynamic technical and economic systems, International Conference on Modern Problems of Radio Engineering, Telecommunications and Computer Science, TCSET 2002, 1015877, 2002, pp. 106107. DOI: $10.1109 /$ TCSET.2002.1015877.

[4] Zhou M., Tan Y., Spatial dynamic economic systems modelling and simulation for strategic planning, Systems Analysis Modelling Simulation, Vol. 26, No. 1-4, 1996, pp. 57-68. 
[5] Crookes D.J., Blignaut J.N., de Wit M.P., Esler K.J., Le Maitre D.C., Milton S.J., Mitchell S.A., Cloete J., de Abreu P., Fourie H., Gull K., Marx D., Mugido W., Ndhlovu T., Nowell M., Pauw M., Rebelo A., System dynamic modelling to assess economic viability and risk trade-offs for ecological restoration in South Africa, Journal of Environmental Management, Vol. 120, 2013, pp. 138-147. DOI: 10.1016/j.jenvman.2013.02.001.

[6] Ruth M., Hannon B., Modeling dynamic economic systems: Second edition. Modeling Dynamic Economic Systems: Second Edition, 2012, 326 pp. DOI: 10.1007/978-1-4614-2209-9.

[7] Jurenoks V., Jansons V., Didenko K., Modelling of stability of economic systems using benchmarking and dynamic programming, UKSim 10th International Conference on Computer Modelling and Simulation, EUROSIM/UKSim2008, 4488947, 2008, pp. 295300. DOI: 10.1109/UKSIM.2008.96.

[8] Sohrabi, A.R., Economic analysis of a pumped storage project for iran generating system based on dynamic modeling, $41^{\text {st }}$ International Universities Power Engineering Conference, UPEC 2006, Conference Procedings, Vol. 1, No. 4218637, 2006, pp. 21-25. DOI: 10.1109/UPEC.2006.367708.

[9] Tkachenko I.S., Ishchuk O.R., Modeling of dynamic harmonious development of economic systems, 2nd IEEE International Workshop on Intelligent Data Acquisition and Advanced Computing Systems: Technology and Applications, IDAACS 2003, No. 1249614, 2003, pp. 498-499. DOI: 10.1109/IDAACS.2003.1249614.

[10] Srivastava A., Patil P.R., The future of education, knowledge and skills: The organisation for economic co-operation and development, Journal of Critical Reviews, Vol. 7, No. 10, 2020, pp. 1324-1330. DOI: 10.31838/jcr.07.10.260.

[11] Sanchez-Canales V., Payá J., Corberán J.M., Hassan A.H., Dynamic modelling and technoeconomic assessment of a compressed heat energy storage system: Application in a $26-\mathrm{MW}$ wind farm in Spain, Energies, Vol. 13, No. 18, 2020, 4739. DOI: $10.3390 /$ en13184739.

[12] Abbaspour H., Drebenstedt C., Badroddin M., Maghaminik A., Optimized design of drilling and blasting operations in open pit mines under technical and economic uncertainties by system dynamic modelling, International Journal of Mining Science and Technology, Vol. 28, No. 6, 2018, pp. 839-848. DOI: 10.1016/j.jimst.2018.06.009.

[13] Uehara T., Cordier M., Hamaide B., Fully dynamic input-output/system dynamics modeling for ecological-economic system analysis, Sustainability, Vol. 10, No. 6, 2018, 1765. DOI: 10.3390/su10061765.

[14] Whitehead P.G., Sarkar S., Jin L., Futter M.N., Caesar J., Barbour E., Butterfield D., Sinha R., Nicholls R., Hutton C., Leckie H.D., (2015). Dynamic modeling of the Ganga river system: Impacts of future climate and socio-economic change on flows and nitrogen fluxes in India and Bangladesh, Environmental Sciences: Processes and Impacts, Vol. 17, No. 6, 2015, pp. 1082-1097. DOI: $10.1039 / \mathrm{c} 4 \mathrm{em} 00616 \mathrm{j}$.

[15] Tarasyev A.A., Jabbar J.B., Dynamic Modeling of Labor Migration Impact on the Economic System Development, IFAC-PapersOnLine, Vol. 51, No. 32, 2018, pp. 407-412. DOI: 10.1016/j.ifacol.2018.11.418.

[16] Shao Y., Sun X., Liu X., Yang C., Modeling of dynamic input-output economic systems with multiple delays, 2014 International Conference on Mechatronics and Control, ICMC 2014, No. 7231504, 2015, pp. 1-6. DOI: 10.1109/ICMC.2014.7231504.

[17] Iatagan M., Dinu C., Stoica A.M., Continuous training of human resources - A solution to crisis going out, Procedia - Social and Behavioral Sciences, Vol. 2, No. 2, 2010, pp. 5139-5146.

[18] Benevene P., Cortini M., Human resource strategic management in NPOs: An explorative study on managers' psychosocial training, Journal of Workplace Learning, Vol. 22, No. 8, 2010, pp. 508-521.

[19] Nurunnabi, M.,Transformation from an Oilbased Economy to a Knowledge-based Economy in Saudi Arabia: the Direction of Saudi Vision 2030, Journal of the Knowledge Economy, Vol. 8, No. 2, 2017, pp. 536-564. DOI: 10.1007/s13132017-0479-8.

[20] Wells D., Schminke M., Ethical development and human resources training: An integrative framework, Human Resource Management Review, Vol. 11, No. 1-2, 2001, pp. 135-158.

[21] Simões E., Duarte A-P., Neves J., Silva V-H., Contextual determinants of HR professionals' selfperceptions of unethical HRM practices, European Journal of Management and Business Economics, Vol. 28, No. 1, 2017, pp. 90-108. DOI 10.1108/EJMBE-12-2017-0062.

[22] Valle R., Martin F., Romero P.M., Dolan S.L. Business strategy, work processes and human resource training: Are they congruent? Journal of Organizational Behavior, Vol. 21, No. 3, 2000, pp. 283-297.

[23] Tahir N., Yousafzai I-K., Jan S., Hashim M., The Impact of Training and Development on 
Employees Performance and Productivity-A case study of United Bank Limited Peshawar City, KPK, Pakistan, International Journal of Academic Research in Business and Social Sciences, Vol. 4, No. 4, 2014, pp. 86-98. DOI: 10.6007/IJARBSS/v4-i4/756.

[24] Green, F., The impact of company human resource policies on social skills: Implications for training sponsorship, quit rates and efficiency wages, Scottish Journal of Political Economy, Vol. 47, No. 3, 2000, pp. 251-272.

[25] Tinti J-A., Venelli-Costa L., Vieira A-M., Cappellozza A., The impact of human resources policies and practices on organizational citizenship behaviors, Brazilian Business Review, Vol. 14, No. 6, 2017, pp. 636-653. DOI: 10.15728/bbr.2017.14.6.6.

[26] Hoke E., Taraba P., Peterek K., Human Resources Management in the Corporate Crisis, Chemical Engineering Transactions, Vol. 82, 2020, pp. 133-138. DOI: 10.3303/CET2082023.

[27] Chatzimouratidis A., Theotokas I., Lagoudis I.N., Decision support systems for human resource training and development, International Journal of Human Resource Management, Vol. 23, No. 4, 2012, pp. 662-693.

[28] Wang C., Scientific culture and the construction of a world leader in science and technology, Cultures of Science, Vol. 1, No. 1, 2018, pp. 1-13. DOI: $10.1177 / 209660831800100102$.

[29] Cieslik A., Turgut M-B., Estimating the Growth Effects of 2004 Eastern Enlargement of the European Union, Journal of Risk and Financial Management, Vol. 14, No. 3, 2021, 128. DOI: 10.3390/jrfm14030128.

[30] Arabandi B., Globalization, Flexibility and New Workplace Culture in the United States and India, Sociology Compass, Vol. 5, No. 7, 2011, pp. 525539, DOI: 10.1111/j.1751-9020.2011.00389.x.

[31] Torp S., Reiersen J., Globalization, Work, and Health: A Nordic Perspective, International Journal of Environmental Research and Public Health, Vol. 17, No. 20, 2020, 7661; DOI:10.3390/ijerph17207661.

[32] Hadjimichalis C., An uncertain future for the post-Brexit, post-COVID-19 European Union, European Urban and Regional Studies, Vol. 28, No. $1, \quad 2021$, pp. 8-13. DOI: 10.1177/0969776420968961.

[33] Auti S-D., Patil J., Prefabrication Technology-A Promising Alternative in Construction Industry, International Journal of Science and Research, Vol. 8, No. 8, 2019, pp. 220 - 224. DOI:10.21275/ART2020213.
[34] Belhadi A., Kamble S., Jabbour C-J-C., Gunasekaran A., Ndubisi N-O., Venkatesh M., Manufacturing and service supply chain resilience to the COVID-19 outbreak: Lessons learned from the automobile and airline industries, Technological Forecasting \& Social Change, Vol. 163, 2021, 120447.2 DOI: 10.1016/j.techfore.2020.120447

[35] Babones S.J., Trade globalization, economic development and the importance of education-asknowledge, Journal of Sociology, Vol. 46, No. 1, 2010, pp. 45-61. DOI: 10.1177/1440783309337674

[36] Peri G. (2014). Do immigrant workers depress the wages of native workers? Short-term wage effects of immigrants are close to zero-and in the long term immigrants can boost productivity and wages, IZA World of Labor 2014, No. 42, 2014, pp. 1-10. DOI: 10.15185/izawol.42

[37] Holzer H-J., Immigration policy and less-skilled indigenous and immigrant workers in the United States:Reflections on future directions for reform, 31 pp. Migration Policy Institute (MPI) eds., 2011, Available at <https://www.migrationpolicy.org/pubs/HolzerJanuary2011.pdf>, Access on 31 October 2021.

[38] Kim S., Choi B., The Impact of the Technological Capability of a Host Country on Inward FDI in OECD Countries: The Moderating Roles of Institutional Quality, Sustainability, Vol. 12, No. 22, 2020, 9711, doi:10.3390/su12229711.

[39] Teng L., Tan Q., Ehsani A., Assessing the impact of cultural characteristics, economic situations, skills and knowledge on the development and success of cloud-based e-learning systems in the COVID-19 era, Kybernetes, 2021, DOI: $10.1108 / \mathrm{K}-12-2020-0838$.

[40] Smart A., Smart J., Petty capitalists and globalization: Flexibility, entrepreneurship, and economic development, SUNY series in Anthropological Studies of Contemporary Issues, State University of New York Press, 2006, 325 pp.

[41] Patel P.C., Rietveld C.A., Does globalization affect perceptions about entrepreneurship? The role of economic development, Small Business Economics, 2021, DOI: 10.1007/s11187-02100455-y.

[42] Lauder H., Brown P., Economic globalisation, skill formation and development, Routledge Handbook of International Education and Development, 2015, pp. 303-312.

[43] Mahtaney, P. (2013). Globalization and sustainable economic development: Issues, insights, and inference, Globalization and Sustainable Economic Development: Issues, 
Insights, and Inference, 2013, 235 pp. DOI: 10.1057/9781137024992.

[44] Bernal R.L., Globalization, trade, and economic development: The CARIFORUM-EU economic partnership agreement, Globalization, Trade, and Economic Development: The CARIFORUM-EU Economic Partnership Agreement, 2013, 269 pp. DOI: $10.1057 / 9781137356314$.

[45] Cooke, P., Economic globalisation and its future challenges for regional development, International Journal of Technology Management, Vol. 26, No. 2-4, 2003, pp. 401-420. DOI: 10.1504/ijtm.2003.003389.

\section{Creative Commons Attribution License 4.0 (Attribution 4.0 International, CC BY 4.0)}

This article is published under the terms of the Creative Commons Attribution License 4.0

https://creativecommons.org/licenses/by/4.0/deed.en_US 